\section{Educación cívica y construcción de ciudadanía en el Chile de la pos dictadura, ¿en qué estamos y para dónde vamos?}

Civic education and citizenship building in Chile after the dictatorship, what are we and where are we going?

\section{Roberto Mardones-Arévalo*}

\section{Resumen}

Hacemás de una décadasehavenido discutiendo en Chile, a nivel político y académico, acerca de la pertinencia de (re) instalar la educación cívica en el currículo escolar. Esto, de alguna manera motivado, por la situación de apatía, desinterés y los bajos niveles de participación política demostrados por la ciudadanía desde el retorno a la democracia. Así, el objetivo de este trabajo es analizar de manera crítica, a partir de la

Departamento de Sociología y Ciencia Política, Universidad Católica de Temuco, rmardones@uct.cl historia política, la trayectoria y construcción de la educación cívica y la ciudadanía. La pregunta que guía el argumento es ¿en qué medida la forma en que se concibe la educación cívica influye sobre la construcción de ciudadanía? Nuestro supuesto es que, históricamente, se ha propendido hacia la generación de una ciudadanía pasiva y que, el retorno a la democracia, no implicó un cambio al respecto. Por tanto, su implementación, no ha significado una solución a la situación observada.

Palabras clave: Educación cívica, Ciudadanía, Participación política, Democracia.

\begin{abstract}
More than a decade ago, Chile has been discussing, at a political and academic level, the relevance of (re) installing civic education in the school curriculum. This, in some way motivated, by the situation of apathy, disinterest and the low levels of political participation demonstrated by the citizens since the return to democracy. Thus, the objective of this paper is to critically analyze, from political history, the trajectory and construction of civic education and citizenship. The question that guides the argument is to what extent the way in which civic education is conceived influences the construction of citizenship? Our assumption is that, historically, it has tended towards the generation of a passive citizenship and that, the return to democracy, did not imply a change in this regard. Therefore, its implementation has not meant a solution to the situation observed.
\end{abstract}

Key words: Civic education Citizenship, Political participation, Democracy. 


\section{Introducción}

La educación cívica, como contenido básico de la construcción ciudadana, es algo que se puede observar en Chile desde inicios del siglo $X X$. La implementación de la asignatura ha sufrido cambios en el tiempo: independiente, subsumida en otras asignaturas, nombres distintos, etc. También varió la cantidad de horas que se le asigna y también los niveles en los cuales se imparte. Más allá de cómo se ha implementado, lo que prima, es la idea de una ciudadanía como pertenencia a una comunidad, poniendo énfasis en elementos simbólicos.

En los últimos 20 años, se ha visto a la educación cívica como una posible respuesta al retrotraimiento ciudadano, el cual se expresa en bajos niveles de participación política tanto convencional (elecciones, militancia política) y no convencional (marchas, firma de petición, organizaciones que luchan por un ideal). Se han realizado varias intervenciones al currículo con el mencionado fin, pero el conocimiento cívico de los estudiantes chilenos de octavo grado, último de la educación primaria, se mantiene en niveles por debajo de la media internacional. Asimismo, los niveles de involucramiento ciudadano, siguen siendo bajos.

Teniendo en cuenta el contexto mencionado, nos preguntamos ¿en qué medida la forma en que se concibe la educación cívica influye sobre la construcción de ciudadanía? Nuestro supuesto al respecto es que la idea que ha primado está vinculada a la pertenencia más que a la titularidad de la participación política. Esto ha generado una ciudadanía pasiva, que se motiva en situaciones excepcionales.

Nuestro objetivo general es analizar la trayectoria y construcción de la educación cívica y la ciudadanía en Chile. En términos específicos vamos identificar hitos relevantes dentro de la trayectoria de la educación cívica y describiremos las cualidades de la idea de ciudadanía.

Este trabajo es una línea que se desprende de una investigación más acabada sobre desafección y participación política, por tanto, se ha realizado un proceso acucioso de revisión bibliográfica secundaria y de datos obtenidos de distintas instituciones, tanto agregados como desagregados. Para esta línea sobre educación cívica y ciudadanía, hemos tomado libros, documentos oficiales del Ministerio de educación de Chile (Mineduc) y leyes, particularmente la 20.911, que crea el plan de formación ciudadana. Además, trabajamos con datos secundarios de los estudios internacionales de educación cívica contenidos en informes del Mineduc (2010 y 2018), de los estudios realizados por el Programa de naciones unidas para el desarrollo (PNUD 2015 y 2016), de la Corporación Latinobarómetro (2017) y de las encuestas de juventud realizadas por el Instituto nacional de la juventud (INJUV 2009 y 2015). Todas las fuentes antes nombradas, aportan valiosa información para el tema que presentamos en este trabajo.

\section{Educación cívica, la mantención del statu quo}

La educación cívica, no solo es tema de moda y vigente en la discusión educativa y política desde hace más de una década, surge como preocupación a inicios del siglo XX. Una primera aproximación a la temática la encontramos el año 1912, momento en que es incluida en el currículo escolar como una asignatura independiente en 
quinto y sexto año de humanidades. (Mineduc 2004)

En 1924 es publicada la obra "Cartilla de educación cívica" del político liberal Malaquías Concha, la cual tenía por objetivo servir de guía para profesores en la formación de sus alumnos en este ámbito. El autor tenía el convencimiento de que "es necesario que los futuros ciudadanos se hallen preparados seriamente para la vida pública" agregando que "la democracia debe ser instruida de lo contrario sería el peor gobierno y conduciría al país a la ruina" (Concha 1924: 3). Se prepara para la vida pública y se aprende a vivir en democracia, este es el resultado de la educación cívica.

Si bien Malaquías Concha es considerado un progresista para su época, las pautas sobre las que se mueve dejan ver la influencia del contexto en el cual vivió. Las cualidades de civismo incluyen "el amor a la patria y a la libertad, la abnegación por la familia y por sus conciudadanos, el respeto al derecho y a la justicia, el anhelo de rendir servicios al bien público" (Concha 1924: 6) elementos que sustentan el tipo de dominación tradicional vigente en la época.

Lo anterior vinculado a un contexto en el cual la oligarquía terrateniente no cree en la democracia y sí en el mantenimiento de sus privilegios. De esto da cuenta el hecho que, en la práctica, la educación cívica se utilizara para consolidar los cimientos de un sistema excluyente que tomó a la escuela como un espacio de adoctrinamiento de las clases bajas a partir de la construcción de una identidad nacional y una memoria colectiva. En este sentido, recordar, por ejemplo, que el voto solo se hizo universal a mediados del siglo $X X$ y que la representación popular solo fue posible a partir de los hechos ocurridos con la denominada "cuestión social” (Grez 1995).

Desde esta perspectiva, el programa de educación cívica aplicado por el Estado de Chile en sus escuelas primarias, puso énfasis en la enseñanza de ese amor a la patria, a la cual se refiere Concha, a partir del culto a los héroes (de la Guerra del Pacífico, por ejemplo) y los emblemas (bandera, escudo, himno), llevado a cabo en actos realizados al interior de las escuelas, ensalzando fechas consideradas hitos en la construcción del Estado - nación, como las fiestas patrias.

La educación cívica está orientada al afianzamiento de una clase, la oligarquía, lo cual se reflejaba en una práctica educativa que diferenciaba entre ciudadanos de primer y segundo nivel. Los primeros, preparados para gobernar y hacerse cargo del aparato estatal; los segundos, preparados para la obediencia, la disciplina y dar la vida por la patria. De hecho, eran estos los que hacían el servicio militar obligatorio, implementado en $1900^{1}$, puesto que los primeros evadían esa responsabilidad.

Se enseñaba una ciudadanía con énfasis en responsabilidades y derechos, poco del ejercicio de la misma.

\section{Más que enfatizar en la defensa y ampliación de los derechos, se insistía en las obligaciones tales como la inviolabilidad de la propiedad privada, el respeto a la ley y a la Constitución, el pago de contribuciones de bienes raíces y el servicio militar $^{2}$}

De esta forma, se estructuró entre quienes asistían a las escuelas públicas primarias, una

Ley 1462 De reclutas y reemplazos del ejército y la armada. https://www.leychile.cl/Navegar?idNorma=212586 
ciudadanía cuyo eje de comportamiento era el orden y la obediencia. No había profundización de los contenidos, ni mucho menos crítica o cuestionamiento al orden establecido.

En 1955 se introduce un cambio respecto de lo implementado en 1912. Se agrega "Consejo de curso". Esta asignatura tenía por objetivo ser un espacio para experimentar las dificultades que se presentan al elegir autoridades y administrar un gobierno (Castro, 2013; Castro \& Holz, 2016; Mineduc, 2004). En este sentido, esta asignatura da cuenta de la intención de introducir una práctica complementaria a lo que se veía en la teoría. La pregunta es si agregarla implica un cambio en el fondo, tanto en términos conceptuales como en la práctica pedagógica.

La asignatura fue subsumida en la materia "Ciencias sociales", dejó de ser independiente y se dividió en dos: "Introducción a la economía" e "Introducción a la ciencia política". Junto con esto, los objetivos de la educación cívica se integraron a otras asignaturas y se promovió la creación de los "Centros de alumnos" como una forma de incentivar la práctica cívica. Todo lo anterior como una política de promoción y empoderamiento del pueblo de parte del gobierno del presidente Frei.

El establecimiento de la dictadura militar, significó cambios radicales y una intervención nunca antes vista. Se controló hasta el más mínimo aspecto, llegando al punto de indicar cuales serían los contenidos a tener en cuenta en la asignatura de historia, considerada punto clave. De hecho, "el propio general Pinochet corrigió personalmente el programa de historia y geografía para octavo año" (Reyes 2013: 34). Además, y con el fin de sentar las bases del régimen, "la Constitución de 1980 comenzó a ser tratada como materia aparte de la asignatura de historia, en la sección de educación cívica" (Reyes 2013: 34).

Hasta la instalación de la dictadura militar la trayectoria de la educación cívica en Chile no había sido algo vinculado a la formación de una ciudadanía empoderada, activa, interesada en los asuntos públicos, en definitiva, informada y con opinión. La excepción la encontramos durante el gobierno del presidente Frei, pero no se alcanza a visualizar su impacto.

Además, lamentablemente no tenemos datos que nos permitan comprobar si las medidas curriculares implementadas desde 1912 hasta el golpe, tuvieron algún impacto en la participación política y en la consolidación de una ciudadanía activa. La posterior instalación de los militares y la proyección de la dictadura, corta el proceso de socialización política, comenzando un proceso de despolitización forzada.

Lo anterior nos lleva a plantear que, si bien la dictadura militar tuvo un impacto negativo en la sociedad chilena, hay elementos que son parte de su cultura política. En este sentido, al parecer, la larga tradición democrática no sería cierta, dado que, por una parte, los procesos más profundos de cambio en ese sentido, se comenzaron a realizar a mediados de los '50 y quedaron truncos con el golpe militar. Por otra parte, "tan solo tomando en consideración la continuidad institucional, no llegamos a tener nunca un periodo de al menos 50 años de estabilidad" (Correa 2000: 117). A esto se debe agregar que el retorno a la democracia en 1990 no trae consigo cambios radicales al sistema político, más bien se mantiene el statu quo. En cuanto a la educación cívica, planes y programas legados del régimen militar se mantuvieron hasta fines de los ' 90 . 


\section{Educación cívica como complemento de la socialización política.}

A fines de los 90 y principios de los 2000 comienza una nueva etapa para la educación cívica. ¿Dónde está lo nuevo y qué es lo que se busca cuando se dice que hay que implementarla? ¿Cuál es el diagnóstico que se ha hecho? ¿Qué es lo que se quiere solucionar o a qué se pretende dar respuesta?

Desde nuestra perspectiva, la temática se puede abordar considerando dos aspectos: uno vinculado a cuestiones relativas a la contingencia política como, por ejemplo: el desinterés y escasa participación ciudadana en política, los bajos niveles de confianza tanto en las instituciones democráticas como en la clase política y el impacto que esto tiene en el sistema democrático; el otro, relativo a la opción que el Estado chileno ha desarrollado desde inicios del siglo XX y hasta el golpe militar.

En cuanto a lo primero, es cierto que la tendencia en el Chile de la post - dictadura es el desinterés acompañado por la retirada del espacio público por parte del sujeto político. En este sentido, desde mediados de los ' 90 , se nota un decaimiento constante de la participación política, desinterés en la misma, bajos niveles de confianza institucional y en las elites al igual que bajos niveles de confianza interpersonal, cuestiones que se encuentran respaldadas en datos de distintas instituciones ${ }^{3}$. Algunos denominaron a este fenómeno desafección

Según datos del PNUD (2016), el 16\% de los encuestados afirmo haber asistido a una marcha o manifestación política, firmar una petición, $13 \%$ y participar en una huelga el $12 \%$. En cuanto a la confianza, según Latinobarometro (2017) partidos políticos, congreso y gobierno superan el $70 \%$ en la alternativa poco más nada. Respecto a la confianza interpersonal, prima la alternativa nunca se es lo suficientemente cuidadoso, sobre un $70 \%$. política (Mardones 2014) y lo relacionaron tanto con cuestiones de índole institucional, por ejemplo, la no inscripción en los registros electorales, comonoinstitucionales, porejemplo, asistir a marchas o pertenecer a organizaciones que luchan por un ideal. Lo anterior con especial énfasis en los más jóvenes ${ }^{4}$.

La situación observada dice relación con que, del fervor de los '80, se pasó a la desmovilización, cuestión que se fue acentuando a medida que avanzaba la democracia recién recuperada. Entonces, en vez de abrirse los espacios de discusión y participación activa de parte de los ciudadanos, se generó el fenómeno contrario lo cual, de una u otra forma, dio pie para pensar que lo que estaba en falta era la educación cívica.

A lo anterior se agrega los deficitarios resultados obtenidos en el primer estudio internacional de educación cívica al cual se sometió Chile en 1999. Este, ubicó a los estudiantes de octavo grado de educación primaria en el lugar 27 de 28 países observados, con un puntaje promedio bajo la media internacional (Mardones 2012). Esto, más la situación observada desde mediados de los '90, dio pie a la discusión acerca de la necesidad de (re) instalar la educación cívica en el trayecto formativo de niños y jóvenes, esta vez en forma transversal, es decir, presente en todo el proceso formativo. Probablemente se vio en la posibilidad de desarrollar estos temas, una salida plausible a la problemática.

En cuanto al segundo aspecto, es decir, la opción que el Estado chileno ha tomado

Según datos de la octava encuesta de juventud (2015), el 58\% de los jóvenes encuestados no asistió a votar para las elecciones de 2013; el 5,4\%, dice pertenecer a alguna organización o agrupación que defiende una causa o ideal; el 22,7\% afirmó haber participado en alguna manifestación social, www.injuv.cl. 
respecto de la educación cívica, lo que se observa, como proceso histórico, es una opción vinculada a una ciudadanía como membresía, es decir, potenciar la idea de pertenencia a una comunidad. Esto implica recurrir a "un puñado de creencias simbólicas e irreflexivas que dotan a las personas de la convicción de que pertenecen a una misma comunidad de origen" (Peña 2015: 32) lo cual queda refrendado con lo que hemos dicho en párrafos anteriores respecto de Malaquías Concha. Desde esta perspectiva, podríamos decir que este tipo de educación cívica apunta a generar sujetos pasivos que aprenden pasivamente, la noción de ciudadanía activa no está presente.

Esto significa que, en principio, hay que generar un cambio en cuanto a lo que se ha entendido por educación cívica hasta ahora, esto es, un instrumento que permite forjar la idea de una comunidad vinculada por una serie de valores y símbolos que propende al mantenimiento del statu quo. Desde esta perspectiva, se hace necesario cambiar el sentido o el énfasis que se ha puesto y agregar otra dimensión, aquella que entiende a la ciudadanía como el ejercicio de la titularidad de la participación política (Peña 2015).

Entenderla de esta forma "requiere virtudes como la tolerancia, la disposición al diálogo y una cierta capacidad reflexiva" (Peña 2015: 32) algo que supone un desafío dadas las características de la sociedad chilena y respecto de cómo se ha entendido la relación Estado - ciudadano y entre ciudadanos. Esta es una situación marcada por la influencia del neoliberalismo y las relaciones de consumo, legado de la dictadura militar y mantenido por los gobiernos democráticos.

Ahora bien, ya sea por el efecto negativo para la democracia o por el rumbo tomado por el
Estado chileno hasta ahora, la educación cívica debe enfocarse en el contexto actual. De ahí que la idea que en general circula, y se repite en distintos foros, es que la educación cívica debe vincularse con el aprendizaje de la vida en comunidad democrática, se entiende que

\begin{abstract}
la ciudadanía y el desarrollo democrático tienen como uno de sus factores clave a la educación. Como quiera que se los entienda, ambos se cimientan en valores y competencias de los individuos, como en las prácticas de cooperación y conflicto que caracterizan sus acciones colectivas (Cox et al 2014: 2)
\end{abstract}

Por tanto, al parecer, tampoco es algo que exclusivamente se vincule con la acción que se pueda emprender en la escuela, es algo que la sobrepasa. No obstante, es necesaria su formalización e inclusión en el trayecto formativo.

¿Por qué es importante incluirla? Porque cumple un rol de socialización política que, como proceso, atiende a cuestiones de diversa índole e influyen en ella elementos como la familia y amigos, que van moldeando las actitudes, en este caso, hacia la política. Si bien hay un efecto del entorno sobre el individuo, esto no quiere decir que este no realice sus propias evaluaciones acerca del mismo, lo cual puede ponerlo en contradicción con algunos elementos. En este sentido,

\footnotetext{
se reivindica aquí la capacidad del sujeto para trabajar con la sociedad y dotar su conducta de un cierto perfil propio, sin desconocer el impacto que ejerce la sociedad sobre el individuo (Tapia 2003: 74).
}

De hecho, es esperable que esto ocurra, en el entendido que de esa contradicción surgen cuestionamientos que motivan la posibilidad de cambio. De esto podríamos colegir que uno de los problemas de la sociedad chilena tras el retorno a la democracia es que esta se instaló 
en función del consenso (Moulian, 1997). Este, por una parte, impide la realización de cambios profundos, los partidos operan con extrema cautela; por otra, en el mediano y corto plazo, genera la imposibilidad de notar las diferencias en cuanto a las alternativas políticas, quedando la impresión que da lo mismo quien salga electo. En este proceso de socialización política tiene mucho que ver la cultura política entendida como

orientaciones específicamente políticas, posturas relativas al sistema político y sus diferentes elementos, así como actitudes relacionadas con la función de uno mismo dentro de dicho sistema (Almond y Verba 1992: 179)

Estas pautas de orientación y actitudes relativas al sistema político, según Almond y Verba (1992), apuntarían en tres dimensiones: cognitiva, afectiva y evaluativa. Estas tres cuestiones son de orden subjetivo dado que incluyen: creencias, percepciones, sentimientos, juicios y opiniones sobre el sistema político. Por tanto, la pregunta que surge es ¿cómo pasar de un tipo de cultura política a otra?

Siguiendo a Almond y Verba (1992), la cultura política chilena podría ser clasificada como de súbdito - participante. ¿Por qué? Porque lo que ha se ha observado en cuanto al comportamiento político ciudadano en más de dos décadas de gobiernos democráticos, es una relación pasiva con el sistema político y una escasa aproximación a los objetos políticos. (Toro y Mardones 2016)

¿Cómo salir de esta situación de súbdito participante? Lograrlo requiere del ejercicio cívico ciudadano, esto referido a que en una sociedad democrática se debe fomentar la discusión, el intercambio de opiniones y la agregación y articulación de demandas. Todo esto es lo que Putnam (2011) denomina virtudes cívicas de asociación y participación. Estas, son propias de una sociedad en la cual priman redes horizontales fundadas en la confianza y en la convicción de que la acción cooperativa genera muchos más dividendos que la individual.

Esto requiere una cuestión previa, precisar qué tipo de ciudadanía es la que se pretende generar. Al respecto, por lo menos hay tres corrientes a tener en cuenta. Por una parte, la liberal, donde la ciudadanía viene a ser una cuestión legal y formal; luego en la versión republicana, la ciudadanía requiere de una formación en términos educativos, eso dado que, "exige....una actuación o práctica, y no solo el reconocimiento de determinados derechos" (Tapia 2003: 63); finalmente, el comunitarismo cívico que sitúa como eje a la comunidad donde el individuo vive, para esta corriente es una "práctica de compromiso orientada a la participación en el ámbito público, la formación de virtudes y la articulación moral del bien público" (Tapia 2003: 67)

Desde esta perspectiva, y en virtud de lo anterior,

la ciudadanía alude a la dimensión pública de los individuos, en un abanico que va desde su condición eventualmente pasiva de titular de derechos, hasta sus variadas formas de intervención pública (Cheresky 2011: 163),

Por tanto, tal como consigna el republicanismo $y$ el comunitarismo $y$, como se dijo en párrafos precedentes, pensar en educar cívicamente involucra pensar activamente y en términos holísticos, con una práctica educativa dinámica. De esta forma, una posible aproximación a la educación cívica implicaría comprenderla como "el conjunto de prácticas educativas que conducen al aprendizaje de la ciudadanía democrática" (Pedró 2003: 239), esto en el entendido que es necesario 
generar competencias que permitan la vida en comunidad cívica.

Lo anterior, sobre todo, en la perspectiva de que el Chile actual reúne tres generaciones con miradas, perspectivas y expectativas distintas y distantes: la primera, es la de aquellos que vivieron el régimen anterior a la instalación de la dictadura militar. Estos tenían ciertas expectativas en cuanto a la recuperación de la democracia en términos comparativos, las cuales debieron ajustar al contexto, de no ser así, tendrían que lidiar con la frustración. La otra generación es la de aquellos que nacieron en dictadura, con expectativas distintas al grupo anterior, sobre todo, respecto de qué es lo que la democracia implica. Además, tuvieron que aprender a vivir en un sistema político abierto y globalizado. Finalmente, están aquellos que no tienen punto de comparación, probablemente tampoco expectativas, dado que nacieron en este esquema democrático y han vivido los avatares del mismo.

Según Mardones (2012), en este último segmento se encuentran los jóvenes, cuya socialización política ha sido precaria y se han hecho parte de esta cultura política de súbdito - participante, sin posibilidad de aprender, producto de la indecisión de las autoridades, qué implica la vida en democracia, el valor de la misma, la importancia de la participación política, la heterogeneidad del entorno, etc.

En este sentido, la educación cívica debe apoyarse sobre "una serie de valores que le den sustento para que se integre no solo como una forma de gobierno sino también como una forma de vida, la cual busque promover la cultura democrática" (Tapia 2003: 62). Esto es muy importante dado que los valores van cambiando, las prioridades y los temas también, surgen nuevas demandas que el sistema político debe absorber y que los ciudadanos deben saber expresar utilizando los distintos canales institucionales y no institucionales que estén a su disposición. Esto último da cuenta, a su vez, de la importancia de la participación política, la cual ha disminuido en forma constante en el Chile democrático, no solo en términos convencionales, sino también no convencionales.

Desde esta perspectiva, en el debate de los últimos quince años el tema vinculado a la educación cívica ${ }^{5}$, ha estado presente sin arribar a decisiones claras respecto de la misma, pero se sigue creyendo que es importante y que hay que incentivarla. El problema es que los números no acompañan. Efectivamente, en 2009 y 2015 Chile se sometió nuevamente al estudio internacional de educación cívica. Los resultados no mostraron cambios, el país se mantiene bajo el promedio internacional en conocimiento cívico de los estudiantes de octavo grado de enseñanza básica ${ }^{6}$.

En función de lo anterior, la pregunta que surge es ¿qué ha hecho Chile por el tema? Según Cox "la reforma curricular de los noventa significó en Chile un cambio de paradigma respecto a la educación cívica tradicional" (Cox 2005: 87). El autor se refiere a la reforma que se llevó a cabo tras la dictadura, la cual se comenzó a implementar en 1997. Ciertamente se realizaron cambios profundos y necesarios a unos planes y programas que venían desde

\footnotetext{
Deja de llamarse así en 1998 cuando es nombrada "Formación ciudadana". Según los expertos esto tiene que ver con una ampliación conceptual y práctica. (Castro y Holz 2016)

$6 \quad$ Mineduc (2010); Mineduc (2018).
} 
la dictadura, desde esta perspectiva, cualquier reforma sería radical.

En lo que concierne a la materia educación cívica, habría que haber pensado el tipo de ciudadano que se requería para el nuevo contexto. ¿Por qué decimos esto? Porque en dictadura la inclusión en el currículo escolar de la educación cívica obedecía a un propósito, colocar en escuelas y liceos la recién instalada Constitución del '80 que sentaba las bases del régimen. Es decir, tal como ocurría a principios del siglo $X X$, era una materia para adoctrinar y en este caso, además, para validar y legitimar el régimen militar.

Tomando los argumentos de Riba (2010), la educación cívica debería ser emancipadora, en tanto y en cuanto, entrega elementos para ser autónomo, capacidad de colaborar en pro de la consecución de un fin, para no vivir subyugado. Es también activadora, invita a movilizarse, a contactarse, a salir del espacio de confort por un fin más amplio. Permite y colabora en la generación de una actitud crítica, con el entorno y consigo mismo, lo cual permite avanzar. Finalmente, es dinámica, se adapta a los distintos contextos. De esto se desprende que es un proceso de educación constante, tal como dijimos, más allá de lo formal que entrega la escuela.

Los cambios realizados al currículo fueron varios, incluyendo el cambio de nombre de la asignatura y que esta fuera transversal. Posteriormente, la Comisión Nacional de Formación Ciudadana ${ }^{7}$, sugirió que, si bien la formación ciudadana debía seguir siendo transversal, había que darle coherencia y sistematicidad. Por lo visto, no

Creada el año 2004, durante el gobierno de Ricardo Lagos. había una correcta apropiación del currículo por parte de los docentes y planteó "la necesidad de un cierre centrado en conocimiento de la institucionalidad y el proceso político en $4^{\circ}$ Año Medio" (Castro \& Holz, 2016, p. 4) que corresponde al último año de la secundaria. En 2007 se comenzó a realizar una revisión del currículo implementado a fines de los '90, la cual concluyó en 2009.

Loanterior quedó reflejado en la implementación de la Ley 20.911 que "crea el plan de formación ciudadana para los establecimientos educacionales reconocidos por el Estado"8. Este plan implica una exposición más explícita de la formación ciudadana, sigue siendo vista como un proceso, pero, además, sale del ámbito del aula, ya que se deben implementar actividades y talleres extra programáticos. Asimismo, se crea una asignatura a ser impartida en tercero y cuarto de enseñanza secundaria, cursos finales de la educación formal en Chile (División de Educación General, 2016), lo cual indica que se está pensando en un cierre del tema.

La implementación de esta Ley no ha estado exenta de críticas, dado que ha generado muchas dudas en las comunidades educativas respecto de cómo llevarla a la práctica. Esto no solo en términos teóricos (conceptos, materias a revisar) y didácticos (como enseñarlos en la sala de clases, por ejemplo), sino también respecto del seguimiento y asesoría por parte del Ministerio de Educación.

Si bien no se puede negar que se han generado cambios orientados a soslayar la situación relativa a los bajos niveles de conocimiento

\footnotetext{
Esta fue promulgada el 28 de marzo de 2016.
} 
cívico y, además, se sigue viendo a la formación ciudadana como una forma de atacar los bajos niveles de participación política, lo que tampoco se puede negar, es que se ha fracasado, así lo indican los datos. Desde esta perspectiva cabe preguntarse si a la clase política le interesa propiciar un ciudadano involucrado.

El orden político instaurado con la modernidad y el triunfo de los principios liberales, impusieron una lógica de gobierno representativo democrático, donde el voto y las elecciones se transformaron en la manera de resolver los conflictos políticos de la clase política, cuestión que se consolida con el paso del tiempo. Asimismo, a medida que pasa el tiempo la política se profesionaliza y cada vez aparece más desligada de la ciudadanía.

En el Chile de hace más de dos décadas se habla de una crisis de la representación que se manifiesta en que los políticos no rinden cuenta de sus actos y la ciudadanía no les hace rendir cuenta. Algo que parece participativo, finalmente, no lo es, todo indica que hay esfuerzos ingentes por generar las condiciones para que la ciudadanía no participe y que cada vez se aleje más.

¿Por qué esa obsesión por dejar a la ciudadanía al margen de la participación política? Es indudable, para dejarlo todo en manos de la clase política, porque la ciudadanía ni sabe ni entiende (Rubio 2007: 145).

Todo indicaría que no hay interés en que la ciudadanía sea educada en términos políticos, y se reproduce, tal como lo indican los estudios mencionados, una brecha entre quienes tienen acceso a una educación de calidad y aquellos que no, estos no están interesados, no participan y son los más perjudicados por el sistema. Los excluidos lo siguen siendo.

\section{El ciudadano chileno, una construcción pauteada.}

Lo anterior nos lleva a preguntarnos y cuestionarnos acerca de qué tipo de ciudadano se ha construido / formado en Chile. Un breve repaso al proceso de construcción en términos histórico - políticos nos muestra una arquitectura que no propende hacia el desarrollo de competencias ciudadanas en cuanto a la práctica de la misma, en el sentido, como se mencionó en párrafos anteriores, de la generación de virtudes cívicas. Más bien lo que se nota es un modelamiento liderado por la institucionalidad que, de una u otra forma, apunta hacia la recepción pasiva de ciertos parámetros que tienden hacia el inmovilismo.

Así, en un primer instante, los ciudadanos serán los criollos, aquellos hijos de españoles nacidos en Chile. Un grupo pequeño que, de alguna forma, empuja el proceso de independencia en función de su demanda de acceso a puestos de poder, los cuales les habían sido vedados dado que eran nombrados desde España. Posteriormente, son estos los que conformarán una incipiente clase política que se irá afincando a medida que avanza el siglo XIX.

La situación tiende a cambiar a finales del siglo XIX y principios del XX producto de la aparición de la "cuestión social", que no es otra cosa que el reclamo de inclusión de los desposeídos, de los dejados de lado por parte del naciente sistema político. Las demandas tienen que ver con cuestiones de orden laboral, como la jornada, condiciones de vida, higiene, etc.

En términos de derechos políticos, la reforma electoral realizada en 1874, implica una apertura. Se extiende el sufragio "a quienes supieran 
leer y escribir, sin exigírseles comprobación de ingresos, rentas o título de propiedad" (Valenzuela 1997: 217), pero todavía está muy lejos de lograr una participación universal. Excluye a las mujeres, los analfabetos y, si lo comparamos con la actualidad, quedan fuera todos aquellos que tienen entre 18 y 20 años, lo cual solo cambiará a fines de la década de los '60 del siglo XX.

Desde este punto de vista, si bien se producen cambios, no podríamos decir que la ciudadanía se concibe como activa y participativa respecto de la toma de decisiones. Esto, habida cuenta de que es la oligarquía terrateniente la que dirige los designios del naciente país y, si bien ha ido ampliando la base en términos de la elección de representantes, esto dista mucho de ser una democracia representativa.

Respecto de lo anterior, sintomático es que durante el siglo XIX fueron los miembros de la oligarquía terrateniente quienes se turnaron en el poder "siempre triunfaron los candidatos del gobierno de turno y, dado el reducido número de votantes, todo el proceso eleccionario prácticamente no tenía impacto en las inclinaciones políticas de las grandes masas" (Valenzuela 1997: 217). Es decir, no existe la idea de un sujeto político, ni mucho menos la idea de participación política. La mayor parte de los "chilenos" durante el siglo XIX estuvieron excluidos de la política entendida como el espacio de toma de decisiones públicas, no hay una relación entre ese ámbito y el de la ciudadanía activa, más bien se

percibió a la política como un ejercicio de violencia masculina elitaria y hereditaria. Como una alianza de jueces, militares, religiosos y mercaderes, unidos por la cruz, el dinero y la ley, pero, sobre todo, por la espada (Salazar y Pinto 1999: 91).
De esta forma, se construye un concepto excluyente de ciudadano donde un porcentaje mayoritario queda fuera de él, probablemente el único elemento que aglutina es la pertenencia a la nación, a la idea del símbolo de aquella nación que se independiza, que aprende sus ritos haciéndolos parte de su acervo cultural.

Podríamos afirmar que la acción ejercida por el proletariado, por los trabajadores asalariados, cambia el escenario político en tanto, al no sentirse representados, se agrupan en sus propias orgánicas, lo cual puede ser considerado una respuesta al sistema político oligárquico, hay una construcción del sujeto político desde abajo. En este sentido, las cooperativas, las mutuales y las sociedades en resistencia, jugaron un rol fundamental en la articulación de las demandas de los trabajadores y sus familias.

Desde esta perspectiva aparece, de facto, la idea de un ciudadano vinculado con el Estado, pero construyendo su relación de abajo hacia arriba esto, en tanto y en cuanto, la institucionalidad no cuenta con las herramientas para responder a las demandas, la clase política desconoce el problema, no sabe cómo enfrentarlo $y$, probablemente, no quiere hacerlo y en esta circunstancia la movilización y la acción fueron relevantes para lograr los resultados esperados. Ahora bien, dentro de esta dinámica de los obreros había diferencias. Los dos primeros tipos de orgánica, cooperativas y mutuales, son de un corte más asistencialista, la tercera, sociedades en resistencia, más crítica y reaccionaria respecto de la situación que vivían los obreros, veían la necesidad de ir más allá del asistencialismo y cambiar esa situación. Este era un sector influenciado por el anarquismo que no tuvo eco, primando la lógica de las primeras. 
Lo anterior supone un ejemplo de cómo se impone la idea de orden versus ruptura, más la reforma que la revolución, lo cual queda refrendado en que, con el paso del tiempo, la aparición de la Federación Obrera de Chile (1909) y, posteriormente, el Partido Obrero Socialista (1912), proveen a la clase trabajadora de un tipo de organización institucionalizada de lucha por sus derechos ante el Estado. A su vez, este último tomó un rol más activo, pasando a ser un Estado protector, más involucrado con el nuevo escenario planteado por el movimiento obrero, ahora devenido en partido político ${ }^{9}$.

La relación ciudadano- Estado durante el siglo $X X$ fue variando en función de los escenarios que se iban planteando, tanto por el empuje desde abajo, como por las necesidades que va experimentando la clase política de realizar reformas. De esta manera, un hito relevante en esta construcción tiene que ver con la gran crisis económica de 1929. El impacto en Chile fue fuerte y el Estado tuvo que tomar un rol más activo, esto de la mano con una creciente crisis del liberalismo, lo cual dio pie para el flujo de nuevas ideas políticas y económicas.

Aparecen nuevos grupos políticos y se expresan nuevos actores sociales. Así, por ejemplo, se fortalece el sindicalismo en los espacios urbanos, esto bajo el alero de partidos de izquierda, como el comunista (1922) y el socialista (1933). A su vez las mujeres se organizan para luchar por

\footnotetext{
Esto es algo muy interesante por al menos dos razones. Por una parte, a partir de la organización del Partido Obrero Socialista se inicia la época del partido de masas, que altera el juego político oligárquico y lo obliga a adaptarse. Por otra parte, se produce una confusión entre los objetivos del partido y los de la clase trabajadora, no quedo claramente delimitado donde comenzaba uno y terminaba el otro, el partido acapara y encapsula la problemática de los obreros.
}

obtener derechos políticos ${ }^{10}$. Es decir, la década del ' 30 al '50 aproximadamente, da cuenta de una activación importante de la ciudadanía, se podría decir que estamos ante una politización del concepto de ciudadanía, estamos ante un sujeto político activo.

Ahora bien, esto hay que observarlo en perspectiva para no sacar conclusiones erróneas. Son ciertos grupos que presionan, generando participación política ciudadana, con un Estado que se ha transformado en benefactor y empresario, que va en pro de transformarse en un Estado democrático. Esto va a tener su correlato cuando comience el proceso reformista a finales de la década del ' 50 . El primer apronte, aunque tibio, fue el del presidente Jorge Alessandri, un empresario que instaló algo así como un gobierno de los gerentes.

Será el presidente Eduardo Frei quien profundizará y Salvador Allende el que irá un paso más allá. Las políticas de promoción popular impulsadas por el primero, tendieron al fortalecimiento de las organizaciones de base, como los centros de madres y las juntas de vecinos junto con una profunda reforma a la educación. A esto se agrega la ley de sindicalización campesina, que supone un duro golpe a la derecha oligárquica que pierde su feudo, el cual le había permitido mantenerse vigente, no sin problemas, en el escenario político. Respecto del gobierno de Salvador Allende, su programa contaba con la realización de profundas reformas que implicarían un cambio radical del sistema político en el cual el pueblo tenía un rol fundamental, lo cual no se concretó.

En 1935 nace el Movimiento pro emancipación de la mujer chilena, vigente hasta 1953. 
En este breve recorrido, queda la idea de que el avance de la condición ciudadana tiene que ver con acciones de orden institucional que, intencionales o no, van abriendo espacios para que se desarrolle, en la práctica, la ciudadanía. Desde este punto de vista, podríamos decir que la clase política genera cambios que le permiten enfrentar, frenar y controlar el ímpetu de la ciudadanía. Esto, lo lleva a cabo instalando la lógica de la ampliación del sufragio y las elecciones como medio para resolver conflictos políticos en conjunto con la necesidad de institucionalizar las organizaciones que canalizan demandas. Así, la universalización del derecho al voto terminó

\begin{abstract}
anulando toda participación ciudadana, individual - colectiva, en la toma de decisiones públicas. La "comunidad cívica" fue pulverizada por la individuación electoral y la reducción del ciudadano a la doble condición pasiva de peticionario y beneficiario de políticas públicas (Salazar y Pinto 1999: 94).
\end{abstract}

A lo cual debemos agregar que, como dijimos en párrafos precedentes, la educación cívica, estuvo presente desde inicios del siglo XX, pero no tenía como eje la práctica, sino más bien se apuntaba al aprendizaje de los símbolos vinculados a la nación, por tanto, no podríamos decir que había una política desde el Estado que la promocionara.

En función de lo anterior, podríamos afirmar que desde el Estado y la clase política dirigente no ha existido una política tendiente a generar un tipo de ciudadanía activa. Así, tal como ocurrió en la Europa de finales del siglo XVIII y principios delXIX, el sistema político chileno se organiza y avanza hacia un tipo de democracia representativa, tal como indica el protocolo del liberalismo.

En momentos de ebullición social, el Estado, como benefactor y empresario, supo controlar a los movilizados, teniendo en cuenta que sus propias políticas públicas habían permitido expandir la educación, disminuir el analfabetismo y consolidar una clase media que tuvo acceso a la educación superior y pudo adquirir un título profesional. Se construye una mini sociedad del bienestar, tal como en la Europa de la post - guerra, que no alcanzó a materializar una democracia participativa.

La dictadura, acabó con todo lo que se había avanzado, tanto institucional como no institucionalmente. Podríamos decir, que estamos ante una despolitización forzada de la sociedad chilena, se rompe el vínculo entre el ciudadano y el Estado, a su vez que se rompen las relaciones ciudadanas. Los derechos básicos fueron transgredidos, partiendo por el hecho de que se instala el estado de sitio para todo el territorio nacional. Con esto se inicia la fase más dura del régimen militar, que tiene su punto más alto con la instalación de la nueva Constitución.

Probablemente, es por esto mismo que llama la atención lo ocurrido en la década de los ' 80 con las protestas. Éstas suponen

\footnotetext{
un proceso de reactivación política, o repolitización de la sociedad chilena que tiene entre sus rasgos más sobresalientes la reactivación de lo que quedaba de los partidos, sus fracciones o sectores, y la aparición de nuevas organizaciones que aspiran al mismo estatus (Yocelevsky 2002: 204).
}

Se produce una repolitización tal como ocurrió en otros momentos de la historia política de Chile, donde los sectores populares se movilizan, comienzan a presionar y demandan cambios. Con su acción obligan a una reacción del sistema político. También es sintomático que termine siendo la clase política y las instituciones las que saquen los dividendos de esa acción. 
Las protestas son un fenómeno que resalta la asociatividad y la cooperación en un momento en que los derechos individuales han sido pasados a llevar. Esta repolitización de la ciudadanía en oposición al Estado que la coacciona, se construye en los sectores populares, que son los más afectados por las políticas implementadas por la dictadura. Son estos "los que pueden sumar a otros de las clases medias e, incluso, de la burguesía, a su movimiento, pero no a la inversa" (Yocelevsky 2002: 207). Esto en el entendido que, tanto las capas medias profesionales, como la clase política, tienen intereses creados y están jaloneados ideológicamente. Por tanto, tienen más problemas para lograr acuerdos e involucrarse en forma activa en las protestas, que van desde formas pacíficas a violentas. En este sentido, tienen más que perder que los primeros.

No obstante, tal como ocurrió en otros momentos de la historia, se impone la lógica institucionalizada y es al ritmo de la clase política que se termina decidiendo el futuro del Chile de la pos - dictadura. Que la clase política se haya adueñado del proceso no es algo nuevo, solo basta mirar hacia atrás y analizar lo ocurrido con el movimiento obrero o con las organizaciones del periodo anterior al golpe militar. Todas, de una u otra forma, sucumbieron al juego político de la clase política organizada en partidos políticos. Esto tiene que ver, probablemente, con que los límites y acción del sistema político están más afianzados, más definidos y acotados que los de la sociedad civil, que se ve penetrada por el primero, el cual impone sus términos. Desde este punto de vista, lo que ocurre con la ciudadanía tras el retorno a la democracia apunta a una atomización social y a un vacío de ética política.
En este sentido, y teniendo en cuenta lo expuesto, cabría preguntarse si la ciudadanía y su ejercicio, particularmente esto último, surge en Chile vinculado a coyunturas específicas y a cuestiones que la afectan directamente. Al parecer, más que una práctica continua, la participación activa es cuestión de momentos. A esto hay que agregar que la situación del Chile de la post - dictadura se inserta en un contexto de un mundo globalizado e interconectado, lo cual marca la agenda interna. Cuestiones como, las redes sociales, el acceso a información en tiempo real, influyen en la configuración de la ciudadanía. Pareciera que, en más de dos décadas de gobiernos democráticos, la ciudadanía está más a la deriva que nunca, bombardeada desde muchos flancos y discursivamente agobiada por una clase política en la cual no confía y que ve cada vez más distante.

Según Hopenhayn (2001), al momento de visualizar a la ciudadanía actual, hay que considerar el impacto que la globalización tiene tanto a nivel político - cultural, como a nivel comercial - financiero. Respecto de lo primero, cuestiones como la construcción de valores democráticos y el respeto por los derechos humanos, lo cual conlleva tolerancia a la diversidad cultural y étnica y el respeto por el Estado de derecho, resultan ser fundamentales. Al respecto, en la década de los 2000 comienza a apreciarse un despertar en este sentido. De todas formas, en lo que a derechos humanos se refiere, hay mucho por hacer.

En cuanto a lo segundo, los efectos a nivel comercial y financiero, se han dejado sentir fuerte. Por una parte, supone una disolución de las fronteras, sobre todo desde el punto de vista de que Chile ha firmado tratados de libre comercio y está inserto en un círculo que 
lo expone a los vaivenes externos, por tanto, crece la vulnerabilidad. Esto pone en jaque la idea de Estado - nación, pero, sobre todo, tiene consecuencias adversas sobre el ejercicio de la ciudadanía y los derechos sociales y económicos.

Lo anterior se observa en el avance de la precarización de la sociedad en todo ámbito. Si lo miramos desde la perspectiva laboral, este espacio es cada vez más inseguro, no hay estabilidad y eso afecta la posibilidad de proyección individual y familiar. En términos sociales, si bien la pobreza disminuye, aumenta la desigualdad, se profundiza la brecha entre una minoría que se lleva el pedazo más grande de la torta, versus la gran mayoría que se reparte lo que queda. La clase media es abundante y, en general, depende del acceso a los servicios financieros, lo cual genera altos niveles de endeudamiento. Según datos del Banco Central, la deuda de los hogares chilenos se situó en un $71 \%$ en 2017 , lo que equivale 3,7 puntos porcentuales más que el año 2016. (Banco Central 2017)

Desde este punto de vista, podríamos estar hablando de una nueva dimensión de la pobreza generada por el sistema neoliberal, basada en un supuesto libre acceso a bienes y servicios, acompañada con un profundo sentimiento de malestar producto del no cumplimiento de expectativas. Esto da cuenta de uno de los problemas del capitalismo, el cual no solo "desfigura al trabajador, sino que deforma su condición de ciudadano, debido a que las premisas del gran capital operan como factor de estímulo de conductas individualistas" (Puerta 2016: 11). En este sentido, los gobiernos que se han sucedido tras el retorno a la democracia, han instalado la idea de una economía social de mercado, que pone mayor énfasis en el bienestar de los más desposeídos. Genera políticas sociales y entrega bonos para atenuar la desigualdad que el sistema ha generado, pero no ataca el fondo, estas medidas son un paliativo.

Lo anterior genera una visión pesimista o realista de las cosas, según sea el cristal con el que se mire. Desde nuestra perspectiva, si bien Chile ha avanzado, hay sinsabores respecto de las posibilidades que ofrecía la vuelta a la democracia en términos de derechos económicos y sociales, cuestiones que no se han concretado. Asimismo, en la dimensión relativa a derechos culturales, nos queda la impresión, que no es algo primordial. Uno de los ejemplos, es la lucha que los pueblos originarios, particularmente el mapuche, han dado para ser reconocidos e incorporados a partir de su diferencia.

El tema de los derechos culturales ha tomado relevancia en los últimos 15 años y se abre paso muy lentamente. La ciudadanía en general, no tiene acceso fluido a esta dimensión, esto no obstante hay iniciativas como el rescate al patrimonio, el incentivo a la realización de ferias costumbristas, pero todavía no está instalado el tema como una cuestión de interés ciudadano. Esta es una dimensión no menor, necesaria de explotar en tanto pone en contacto a la ciudadanía con elementos que le permiten reconocerse y reconocer al otro como interlocutor válido con demandas legítimas.

En función de lo dicho hasta ahora, resulta complicado pensar en la teoría y práctica del ciudadano en circunstancias en las cuales todo apunta a que, sobre todo en la práctica, no hay espacios, pero tampoco está la idea del ejercicio 
de la ciudadanía y qué es lo que ello implica. Esto en línea con la forma de democracia que se instala, una democracia política, que corresponde a la forma más acotada de ella, en la cual prima la dimensión de los derechos civiles y políticos, que se expresa en la noción de representación que, como ya hemos dicho, no hace una buena dupla con la democracia en cuanto a que, básicamente, empobrece al ciudadano.

Desde esta perspectiva, probablemente lo primero que habría que resolver es qué es lo que implica, en la actualidad, la condición ciudadana. Cuando nos referimos a la actualidad estamos pensando en el ciudadano chileno de las dos últimas décadas, ¿cómo y en qué condiciones se ha construido este ciudadano? ¿cuáles son los referentes del ciudadano chileno de la democracia instalada tras la dictadura?

La sociedad chilena es una sociedad de contrastes, desigual y precaria por una parte $y$, por otra, una que da cuenta de un exitoso tránsito a la democracia, de un crecimiento económico nunca antes visto, avance tecnológico, oportunidad de acceso a bienes y servicios. En una primera etapa, que la podríamos situar hasta fines de los ' 90 , la ciudadanía vio como el país se posicionaba y se iniciaba un discurso exitista en cuanto a los logros que cada gobierno iba realizando. Esto, centrado fundamentalmente, en cuestiones de orden macroeconómico. La sociedad chilena ve como se le abren oportunidades y como se construye esta democracia en la cual cohabitan civiles y militares, intentando hacer como si nada hubiera ocurrido. Es esta democracia la que traerá de vuelta a Chile al General Pinochet de su arresto en Londres, la que juzgará a Manuel Contreras y Pedro Espinoza. Paralelamente, la ciudadanía comienza a retrotraerse.
Si bien en los años 2000 continúa el retrotraimiento ciudadano, incipientemente surgen nuevas formas de organización y acción vinculadas con demandas específicas. Son grupos que se organizan por problemas que aquejan a ciertos sectores ciudadanos que, sin ser elegidos para ello, representan una determinada sensibilidad. Desde esta perspectiva, estamos ante lo que Cheresky (2011) denomina auto - representación, la cual surge producto de la lejanía que tiene la ciudadanía del sistema representativo formal. Son agrupaciones espontáneas que se establecen a partir de afinidades temáticas.

Según Avritzer (2014), este tipo de representación corresponde a lo que él denomina advocacy. Aquí el tipo de representación tiene que ver con discurso e ideas. También podría ser lo que el mismo autor denomina representación de la sociedad civil, donde lo que se representa son temas y experiencias. Lo común de ambos, es que corresponden a un tipo de representación no electiva y su forma de manifestar el desacuerdo es la protesta en sus diversas formas: pacíficas, violentas, judiciales, etc.

Por tanto, si bien se nota un cambio en cuanto al involucramiento ciudadano y podríamos hablar de ciertos niveles de politización en algunos sectores organizados de la sociedad civil, sobre todo en la segunda mitad de los 2000, todavía esto no alcanza como para equilibrar la correlación de fuerzas con otros actores estratégicos mucho más cohesionados y con objetivos más claros, como los partidos políticos.

Además, está el hecho de que todavía la profundidad y tipo de demanda dice relación con cuestiones específicas y coyunturales, 
más que cuestiones de fondo. Analizado por bienios, el periodo 2005 - 2006, da cuenta de un $70 \%$ de demanda específica acotada y $30 \%$ respecto de transformación política; para 2007 - 2008, $76 \%$ y $24 \%$ y para $2009-2010,81 \%$ y 19\%, respectivamente (PNUD, 2015: 175). La situación cambia para 2011 - 2012, 55\% y $45 \%$, no obstante, hay que tener en cuenta que esa medición se realiza en pleno momento del conflicto estudiantil, lo cual puede sesgar los resultados al realizar el análisis sobre la contingencia, se pierde objetividad.

$\mathrm{Si}$ bien han surgido nuevas formas de representación y también se han producido manifestaciones masivas de los estudiantes en 2006, con la "Revolución pingüina" y en 2011 con los universitarios, que sin duda generaron un remezón importante en la opinión pública chilena, luego se vuelve a la situación de retrotraimiento ciudadano. Tal como decíamos en párrafos precedentes, el comportamiento político chileno no es lineal, presenta altas y bajas, pero, en general,

los informes que analizan las actitudes políticas de los chilenos, coinciden en señalar que el país cuenta con una ciudadanía muy poco activa y participativa de las decisiones públicas (Toro y Mardones 2016: 93)

La cita anterior refuerza nuestro argumento relativo a la importancia de generar un cambio en cuanto a lo que se entiende por educación o formación ciudadana. Hay que potenciar la dimensión de titularidad de la participación política. Esto se logrará no solo impartiendo la materia en forma transversal, en actividades extraprogramáticas y en los últimos niveles de la educación secundaria, también tienen un rol los profesores que están encargados de implementarla, la comunidad escolar que incluye a directivos, padres y apoderados y, sin duda, el sistema político en su conjunto, que hasta ahora ha fracasado en su intento.

\section{A modo de conclusión}

Observado en perspectiva de proceso histórico político, en Chile se ha concebido una ciudadanía pasiva. La constatación que hacen distintos informes al respecto, evidencia la falta de involucramiento político. A esto se debe agregar los bajos niveles de conocimiento cívico de los estudiantes de octavo grado de educación primaria en los tres estudios internacionales que hemos mencionado. Al respecto, tenemos la sospecha plausible que la forma en que se han implementado los cambios curriculares al respecto, no han cumplido con las expectativas. Si bien los resultados del primer informe eran esperables, dado que eran los legados de la dictadura, los de 2009 y 2015, son aplicados con la reforma en marcha y varios ajustes de por medio a la materia. Ni han subido los puntajes ni ha aumentado el involucramiento político. Los estudiantes que hicieron parte del estudio en 2009, ya cumplieron la mayoría de edad (18) y están inscritos en el registro electoral. Los del 2015, están a punto.

Una cuestión interesante es que son los propios jóvenes quienes perciben la falencia en cuanto a su formación cívica. Según datos del INJUV, una parte importante de ellos

\footnotetext{
cree que debiera mejorar la calidad de la educación cívica impartida en el sistema educativo del país, valor que aumenta conforme lo hace el nivel de ingresos, pero, sobre todo, en la medida que es mayor el nivel educacional (INJUV 2009: 153).
}

Los jóvenes perciben que falta algo en su formación y que debiera mejorar la calidad 
de lo que se imparte ${ }^{11}$. Lamentablemente la cita también deja ver que quienes detectan la falencia, son los jóvenes de mayor nivel socioeconómico, lo cual da cuenta de las brechas educativas. Esto no hace otra cosa que repetir el patrón de inicios del siglo XX, los desfavorecidos se mantienen, y son mantenidos al margen, generándose una ciudadanía de segunda clase.

Esta dualidad respecto de la idea de ciudadanía, provoca una distorsión en los parámetros de medición de lo que significa ser ciudadano, dado que las clases acomodadas, por ejemplo, son educadas o tienen acceso a un tipo de educación que les entrega unas competencias que no tiene la mayoría de los jóvenes. La formación de esa gran parte es deficitaria, para ellos la noción de ciudadanía está vinculada con la nación y la construcción simbólica de la misma. No hay una relación establecida a partir de la importancia, por ejemplo, de la participación en la toma de decisiones, sino más bien en la recepción pasiva de los beneficios que el Estado brinda, prima una idea más asistencialista.

Por tanto ¿es posible cuestionar la calidad del ciudadano chileno, sus aptitudes si el sistema educativo no ha sido lo suficientemente efectivo en su preparación y formación? ¿Podríamos recriminar al ciudadano por su pasividad, por su preferencia por el orden y la política institucionalizada si es eso lo que se le ha inculcado? Creemos que la respuesta a estas preguntas es no. Solo si tomamos la última década, los estudios realizados indican que Chile no avanza en el desarrollo de la temática. Los niños y jóvenes que están asistiendo a escuelas básicas y secundarias que forman parte del sistema de educación pública, es decir, aquellos que pertenecen a los municipios, no están siendo formados con las competencias que les permitan valorar al sistema democrático, su educación, en general, es deficiente.

Si bien lo relativo al involucramiento ciudadano en asuntos de orden político tiende a cambiar a mediados de los 2000, y se nota la aparición de nuevas formas de representación, participación y expresión política, está por verse si esto se constituye en una fuente de cambio para el sistema político. Esto, en el entendido que, en su gran mayoría, el tipo de acción apunta a demandas específicas por sobre las de transformación política. Además, quienes están ejerciendo un tipo de ciudadanía activa no son, necesariamente, los excluidos del sistema. Tal como queda refrendado en el informe del PNUD (2015), son aquellos que tienen un mejor nivel socioeconómico y educativo los que se involucran en política que, si bien pueden empatizar con los más desposeídos, sus intereses y demandas no están directamente relacionadas con las de aquellos. El patrón se repite, el sistema educativo sigue reproduciendo la desigualdad. 


\section{Bibliografía}

Almond, Gabriel, y Sidney, Verba. 1992. "La cultura política". En Diez textos básicos de ciencia política. Albert Batlle (Ed.). Barcelona: Editorial Ariel. 171-201.

Avritzer, Leonardo. 2014. Los desafíos de la participación en América Latina. Buenos Aires: Prometeo Libros.

Banco Central de Chile. 2017. Cuentas nacionales por sector institucional. http://www.bcentral.cl/documents/20143/935472/ CuentasNacionalessectinst_4_trimestre2017.pdf/591680c6044c-3f48-d296-8d5741208bf4

Castro, Luis. (2013). ¿Cuándo se eliminó la asignatura educación cívica? Asesoría parlamentaria. Santiago: Biblioteca del Congreso Nacional.

Castro, Luis y Holz, Mauricio. 2016. De la educación cívica a la formación ciudadana: hitos, distinciones, desafíos y propuestas. Asesoría parlamentaria. Santiago: Biblioteca del Congreso Nacional.

Concha, Malaquías. 1924. Cartilla de instrucción cívica. Santiago: imprenta y litografía Universo.

Corporación Latinobarómetro. 2017. Informe Latinobarómetro. www.latinobarometro.org

Correa, Sofía. 2000. La democracia que tuvimos, la democracia que no fue. Revista de sociología, $n^{\circ} 14,117-120$.

Cox, Cristian. 2005. "La experiencia de Chile". En Educación para la ciudadanía y la democracia para un mundo globalizado: una perspectiva comparativa. Viola Espínola (Ed.). Washington: BID. 85-90.

Cox, Cristian, Bascopé, Martin, Castillo, Juan, Miranda, Daniel y Bonhomme, Macarena. 2014. "Educación ciudadana en América Latina: prioridades de los currículos escolares". IBE Working paper on curriculum issues, 14: 1-41. http://www.ibe. unesco.org/en/resources/ibe-working-papers.

Cheresky, Isidoro. 2011. "Ciudadanía y democracia continua". En Ciudadanía y legitimidad democrática en América Latina. Isidoro Cheresky (Ed.). Buenos Aires: Prometeo. 141-185.

División de educación general. 2016. Orientaciones para la elaboración del plan de formación ciudadana. Santiago: Ministerio de educación.

Grez, Sergio. 1995. La cuestión social en Chile. Ideas y debates precursores (1804-1902). Santiago: Ediciones de la Dirección de Bibliotecas, Archivos y Museos.

Hopenhayn, Martín. 2001. Viejas y nuevas formas de ciudadanía. Revista de la Cepal, vol. 73. pp. 117 - 128.

Instituto Nacional de la Juventud (INJUV). 2009. Sexta encuesta nacional de la juventud. Chile. www.injuv.gob

Instituto Nacional de la Juventud (INJUV) 2015. Octava encuesta nacional de la juventud. Chile. www.injuv.gob

Mardones, Roberto. 2014. "La encrucijada de la democracia chilena. Una aproximación conceptual a la desafección política". Revista Papel Político, vol. 19, n 1. 39-59.

Mardones, Roberto. 2012. "Formación ciudadana, clave de la consolidación democrática". Civilizar. 12 (22). 93-110.

MINEDUC. 2004. Formación ciudadana: actividades de apoyo para el profesor. Historia y ciencias sociales: $1^{\circ}$ básico a $4^{\circ}$ medio. Santiago: Chile.

MINEDUC. 2010. Estudio internacional de educación cívica y formación ciudadana ICCS 2009. Primer informe nacional. Santiago: Chile.

MINEDUC. 2016. Ley 20.911. Crea el plan de formación ciudadana para los establecimientos educacionales reconocidos por el Estado. https://www.leychile.cl/Navegar?idNorma=1088963

MINEDUC 2018. Agencia de la calidad de la educación. Informe nacional ICCS 2016. Santiago: Chile.

Moulian, Tomás. 1997. Chile actual. Anatomía de un mito. Santiago: LOM.

Orellana, Cristian, Bivort, Bruno, Martínez, Soledad, Farías, Fernando, Cárcamo, Héctor, Blanco, Enrique y Pérez, Gabriel. 2015. "Formación ciudadana y participación política en jóvenes de la Universidad del Bío", Chile. Civilizar 15 (28). 119-134.

Pedró, Francesc. 2003. “¿Dónde están las llaves?: investigación politológica y cambio pedagógico en la educación cívica”. En Aprendiendo a ser ciudadanos. Experiencias sociales y construcción de la ciudadanía entre los jóvenes, Jorge Benedicto y María luz Moran (Eds.). España: Ministerio del Trabajo y Asuntos Sociales Injuve. 235-257. http://www.injuve.mtas.es/injuve/contenidos.item. action?id=1007213558.

Peña, Carlos. 2015. "Escuela y vida cívica". En Aprendizaje de la ciudadanía. Contextos, experiencias y resultados. Cristian Cox y Juan Castillo (Eds.). Santiago: Ediciones Universidad Católica de Chile. 25-50.

Programa de las naciones unidas para el desarrollo. 2015. Informe Desarrollo Humano en Chile. Los tiempos de la politización. Santiago: PNUD.

Programa de naciones unidas para el desarrollo. 2016. Auditoría a la democracia. Más y mejor democracia para un Chile inclusivo. Santiago: PNUD.

Putnam, Robert. 2011. Para que la democracia funcione. Madrid: CIS.

Puerta, María. 2016. "Crisis de la democracia. Un recorrido por el debate en la teoría política contemporánea". Revista Espiral, estudios sobre Estado y sociedad, vol. XXIII, n 65. 9-43.

Reyes, Leonora. 2013. "A 40 años del Golpe de Estado: el debate curricular inacabado". Revista Docencia, $n^{\circ}$ 50. 30-46.

Riba, Jordi. 2010. "La educación permanente del ciudadano". En Democracia sin ciudadanos. La construcción de la ciudadanía en las democracias liberales, Victoria Camps (Ed.). Madrid: Trotta. 139-150.

Rubio, José. 2007. Teoría crítica de la ciudadanía democrática. Madrid: Trotta.

Salazar, Gabriel y Pinto, Julio. 1999. Historia contemporánea de Chile, vol. I. Santiago: LOM.

Servicio nacional del patrimonio cultural. Museo de la educación Gabriela Mistral, www.museodelaeducacion.cl.

Tapia, Erika. 2003. Socialización política y educación cívica en 
los niños. México: Instituto Mora - Instituto Electoral de Querétaro. Toro, Sergio y Mardones, Roberto. 2016. La acción ciudadana en tiempos de reforma. Cultura política de la democracia en Chile y en las Américas, 2014: ¿tiempo de reformas? Sergio Toro, Carolina Acevedo y Nathalie Jaramillo. Vanderbilt: Vanderbilt ediciones. 93-114.
Valenzuela, J. Samuel. 1997. "Hacia la formación de instituciones democráticas: prácticas electorales en Chile durante el siglo XIX". Revista Estudios Públicos, 66. 215-257.

Yocelevzky, Ricardo. 2002. Chile: partidos políticos, democracia y dictadura. 1970 - 1990. Santiago: Fondo de cultura económica. 